\title{
Brazil's image as a social representation process
}

\author{
Janaina de Moura Engracia Giraldi ${ }^{1 *}$, lara de Moura Engracia Giraldi ${ }^{2}$ and Alessandro Antonio \\ Scaduto ${ }^{3}$
}

${ }^{1}$ Faculty of Economics, Management and Accounting of Ribeirão Preto (FEA-RP), Univerity of São Paulo (USP), Brazil.
${ }^{2}$ Faculty of Philosophy, Sciences and Letters of Ribeirão Preto (Subarea: Psychology), University of São Paulo. Brazil.
${ }^{3}$ Faculty of Philosophy, Sciences and Letters of Ribeirão Preto (Subarea: Psychology), University of São Paulo, Brazil.

Accepted 14 June 2011

\begin{abstract}
The image people have regarding products' countries of origin can influence their attitudes toward these products or brands. The aim of the present study is to analyze Brazil's image in light of the social representation theory, considering the process of objectivation. In the literature review, concepts such as perception, projection, social representation and countries' images were issued, in order to ground an empirical, qualitative study carried out with Dutch students. The categories identified were: Population, politics, nature, sports and economy. Results showed that a country's image is a multidimensional concept, which includes elements not only related to the products manufactured in this country. These results can have an important implication for companies, who can adopt more effective marketing strategies for their products abroad.
\end{abstract}

Key words: Country image, social representation, Brazil's image.

\section{INTRODUCTION}

The term "country of origin" (COO) refers to the influence of country's information over consumers' attitude toward products made in that country, over beliefs about the attributes of this product or over the attitude and behavior related to purchasing these products. The effects derived from $\mathrm{COO}$ information are considered to be directly affected by the country's image, this study's object. Thus, $\mathrm{COO}$ influences consumers' product evaluations, as well as buying decision (Zhang, 1997), a phenomenon known as "COO effect".

According to Verlegh and Steenkamp (1999), besides being a cognitive cue of the product's quality, the image of a country also refers to emotions, identity, pride and autobiographical memories. These symbolic and emotional connotations transform $\mathrm{COO}$ into an image attribute. Such attributes have shown to be significant Determinants of consumers' preferences and an

*Corresponding author. E-mail: jgiraldi@usp.br Tel: 55 (16) 3602-3903.

Abbreviations: COO, country of origin; SRs, Social representations; GPA, general product attributes; SPA, specific product attributes. important source of brand value. Thus, for these authors, countries' images are mental representations of a country's people, products, culture and national symbols, containing widely shared cultural stereotypes.

For Verlegh et al. (1999), country's stereotypes comprise a series of beliefs regarding its landscape, culture and economy. Examples are "Spain is sunny", "England is traditional" and "Japanese are efficient". Together, these beliefs form a complex mental structure, which enables consumers to make inferences about products' attributes, or to make an initial evaluation of its performance. In this sense, these authors conceptualize country-related stereotypes within three dimensions: Socio-economic structure, culture and geography. However, despite the growing interest in the construct called "country-of-origin image" (there is an estimate that the number of publications on topics relating to $\mathrm{COO}$ at over 1000, with at least 400 of them being published in academic journals (Usunier, 2006), Roth and Diamantopoulos (2009) and Laroche et al. (2005) indicate that the literature has reached no consensus on how to conceptualize and operationalize such phenomena. No systematic analysis of the existing concepttualizations and associated measurement scales of the $\mathrm{COO}$ image are available, leaving researchers with little 
guidance on how to best operationalize the construct in their empirical efforts. As a result, many authors mix the concepts of a specific country's image and the image of the products manufactured in such country.

This lack of consistency in the "country image" conceptual definition can be attributed to the lack of a generally accepted definition of image itself in the psychological image/imagery literature (Lyman, 1984). According to Poiesz (1989), in the consumer behavior literature, there is a number of conceptualizations regarding images/imagery that may overlap in some respects but are basically dissimilar, with different authors referring to images at different levels of abstraction. Images, to Poiesz (1989), can therefore, range from holistic, general impressions to very elaborate evaluations of products, brands, stores or companies, leading to an overlap with other concepts, such as the concept of means-end chains and attitudes.

For Roth and Diamantopoulos (2009), the inconsistency in the definitional domains of the construct "country image" results in a considerable confusion regarding its conceptual specification. They provide a list of researchers that define country image considering different underlying concepts: "Perceptions" (Han, 1989; Nebenzahl et al., 2003), "impressions" or "associations" (Ittersum et al., 2003), "stereotypes" (Verlegh and Steenkamp, 1999), "schemas" (Askegaard and Ger, 1998) and "beliefs" (Martin and Eroglu, 1993), which represent one component of attitude. Despite the diversity in underlying concepts that help explain the formation of a country's image, it is clear that, when assessing purchase alternatives, consumers will be subject to the influence of multiple stimuli, which may be either intrinsic to a product (such as packaging, content or physical properties), or extrinsic to it (communications, price, store, sellers). However, a concept related to image formation that has not been observed in the literature regarding $\mathrm{COO}$ is the "social representation" theory, which is a socio-cognitive framework used to study the social production of commonsense knowledge (Moscovici, 1961).

This commonsense knowledge is directly related to how people interpret or translate the knowledge that is socially transmitted. It offers a set of concrete conceptual tools for addressing the social context from which shared meanings emerge and for capturing the temporal nature of socio-cognitive activity, becoming well suited to analyze country images.

According to Moscovici (1978), two processes initiate representations: Objectivation and anchoring. Objectivation relates to the transformation of concepts or ideas into schemas, which are cognitive structures or frameworks that represent knowledge about a stimulus, its attributes and relationships among these attributes (Taylor and Crocker, 1981). Due to their general nature, these images become "alleged reflections of reality" (Moscovici, 1978). In its turn, anchoring refers to the establishment of a network of meanings around the object, linking it to social values and practices.

This paper aimed at analyzing Brazil's image under the social representation theory, considering the objectivation process. With this study's results, it was intended to develop a new way of analyzing the process of image formation, as well as to provide a wider and deeper knowledge on Brazil's image abroad, given the limited number of articles that has used Brazil as the assessed country. In order to do so, the study present below the concepts and theories that support the study design. Methodological aspects of the search field are then shown, as well as the study's results and conclusions.

\section{DEFINING PERCEPTION}

Research on perception is mixed with the very origin of Psychology as an autonomous science. Since the foundation of the first Experimental Psychology laboratory by Wilhelm Wundt in 1875 until nowadays, several theories have been proposed and used in other knowledge fields, although they lack conceptual homogeneity.

In a wide definition, perception is the process by which stimuli that reach sensorial organs are interpreted. However, this definition contemplates two processes, which are, sensorial organs' activation (defined by classical Psychology as sensation) and these sensations' interpretation, or perception itself. The first studies in this area were conducted by physiologists such as Helmholtz, Weber and Fechner, who tried to explain how sensorial organs were stimulated, as well as the basic conditions for such stimulation to be perceived by the brain (Schultz and Schultz, 1992).

Classical accounts of perception (McLeod, 2007a) tend to only consider the interface between these two processes (organs' stimulation and sensation interprettation) thus conceiving perception in a more passive or simplistic way. Considering this limitation, McLeod (2007b) discusses studies related to the perceptual set theory, which states that perception is active and complex, involving other psychological processes such as selection, inference and interpretation, as well as expectations, emotions, values and culture. Such concept of perception is more present in the administration area, where the interest is focused in the role it plays in more complex processes such as decision taking (Robbins, 1999) and buying-related behavior (Serpa and Avila, 2004; Leão et al., 2007).

In these contexts, it is assumed that consumers tend to form images of brands, stores, companies and countries based on the inferences made from marketing and ambient-related stimuli. An image is then conceived as the total perception of a given object, built along time from information processing (Assael, 1995). Moreover, to Poiesz (1989), the image concept should be used to refer 
to the holistic impression of the relative position of a brand among its perceived competitors.

According to Schiffman and Kanuk (2000), symbolic value is attributed for products and brands, when individuals evaluate them based on the consistency with their own self-images. In this sense, consumers look for preserving or improving their self-images by buying products they consider congruent with these self-images and avoiding products not related to them. This congruity/incongruity issue produces an emotional response that becomes more intense as new information is more discrepant with expectations generated by existing schemas (Mandler, 1982).

Thus, if factors not necessary related to objective, ambient-related information seem determinant for perception - from now on, conceived as an active, interpretative process - two types of phenomena become crucial for business management and marketing areas, namely, the psychological processes of projection and social representations. Basically, the first phenomenon can be considered an individual one that is, more related to personality factors, while the second phenomenon is group-related or social. Both phenomena are discussed below.

\section{The psychological mechanism of projection and its relation to perception}

Laplanche (2001) states that the term "projection" is used in several areas as psychology and neurophysiology, besides psychoanalysis, where this term has acquired a more circumscribed meaning. In a brief definition, projection is understood as a mechanism through which an individual displaces psychological contents outsides him or herself, such as "qualities, feelings, desires and even 'objects' that he or she does not acknowledge or refuses within him or herself" (pp. 374).

Anzieu (1981) refers different uses of the term "projection" in areas such as mathematics or neurology, until Freud has defined it as a psychoanalytical concept. According to Anzieu (1981a; Laplanche, 2001), Freud has first understood projection as a pathological mechanism, observed in psychiatric disorders such as paranoia. Later, in his book "Psychopathology of everyday life" (1904, apud Anzieu, 1981a), Freud describes behaviors in which, although projection is involved, there is not a pathologic component, as it can be observed in superstitions and the animism. In these contexts, individuals would displace a lack of knowledge about common events to magical explanations. This can be seen in old societies' mythology, such as the Greek, for instance, which attributed gods as an explanation for climate variations, soil fertility or the discovery of fire.

Considering that projection is a psychological mechanism where, basically, internal, personal characteristics are perceived outside, and not inside the individual, it can be assumed that such mechanism refers to a variant of perception, where personality factors are involved. In this sense, perception, although being an active process, can be influenced by emotions, desires or anguishes that an individual does not recognize as personal, due to not knowing it or as a defense mechanism against the anguish related to these contents. Based on this principle, several authors have developed psychological tests that elicit projection in order to investigate personality characteristics. The most known example in this sense is the Rorschach test, one of most used psychological tests worldwide (Pasian, 2000).

The importance of projection is also discussed by Robbins (1999) when referring to relationships inside the organization. According to the author, the tendency to attribute one's own characteristics to other people (that is, projection) can distort one's perceptions regarding the others. Business managers and marketing professionals should, so, consider the role of subjective factors in the phenomena related to perception, factors which, even though not related to mental disorders, can lead to judgment or perception errors. As mentioned before, another important perceptive phenomenon related to business management and marketing, that is, social representations, consists of a group-related or social process, which is approached below.

\section{Social representations}

Since Freud's works, social knowledge is understood as interacting with affects and unconscious dynamics (Freud, 1900), once psychoanalysis states that mediations between object and the subject are involved in psychic activity. In this mediation, the subject is recreated in his or her relation to the world. Such human capacity of giving things a new form, via psychic activity, is called symbolic representation. So, representations have their origin from subjects' activity within the world in relation to others, allowing for mediation between the subject and the world, which is discovered and constructed at the same time by this subject.

Representations are factors that produce reality, influencing the way people interpret what happens to themselves and around them, as well as the way they respond when facing something they believe has happened. Once a representation is constituted, individuals will create a reality that validates the predictions and explanations that result from this representation.

Social representations (SRs) can be understood as a way of knowing things, which is socially elaborated and shared. Moscovici (1961) comprehends them as behavior organizers, which influence transmission and assimilation of knowledge, and so acting directly on the definition of both personal and social identities. In this sense, SRs are a form of knowledge among individuals regarding behaviors and communications in the sociohistorical, 
cultural space. For Minayo (1994) "Social representations are not necessarily conscious. They are inserted within the whole society or a specific social group, as something already known and common, which is reproduced and can be perceived in collective and group relations and structures" (free translation).

The processes that build SRs are immersed in social practices and communications all the time, such as in dialogue, discourse, rituals, work patterns, arts and production. SRs are forms of knowledge "socially elaborated and shared, having a practical aim and bringing about the construction of a common reality to a social ensemble" (Jodelet, 1989a). Such representations conceive individuals as transforming actors in their social context, influencing and being influenced by these representations. According to Jodelet (1989b), SRs are a sensible form of knowledge that relates subjects to objects.

For Jovchelovitch (1994), SRs are strategies developed by social actors in order to deal with diversity and mobility, in a world that, although belonging to everyone, transcends them individually. In this sense, such representations are a potential space for common construction, where each subject gets beyond his or her own individuality to enter common life domain, that is, public space. So, SRs do not only origin from social mediations, but become these very mediations. From this standpoint, they express the subject's space in his or her relation with the others, as well as his or her struggle to interpret, understand and build the world.

If, on the one hand, perception is the knowledge about cognitive aspects, SRs, on the other hand, are the individual's knowledge in his or her context. So, comprehending SRs formation is possible from understanding its sociocognitive processes, defined as objectivation and anchorage. As it was mentioned before, objectivation refers to the way constitutive elements of a representation are organized and then materialized. According to Moscovici (1978), objectivation consists of a structuring operation through which an object is given form (or figure), making it concrete, tangible and materialized, that is, turning something untouchable (a representation) into physical and visible (an object). In other terms, objectivation is related to turn concepts into images.

Moscovici (1978) distinguishes three steps in this process: selective construction, structuring schematization and naturalization. During selective construction, subjects take over information and knowledge regarding a given object. On schematization, an imaging structure reproduces a conceptual one, in a visible form, so that a coherent, easily expressible image can be offered, which shows all the elements that constitute the represented object. Finally, during naturalization, abstractions are given full reality. Such process takes place in a "background screen" through which figurative designs acquire concreteness, thus forming a new concept in relation to reality. During objectivation, the object is assessed and given values and qualities, which can vary from aversion to desire.

Besides these processes, SRs are formed through anchorage, through which the object represented (being it ideas, events, people or relations) is cognitively integrated to a former social thought system, as well as the transformations that derive from this operation (Jodelet, 1989). In this sense, to anchorage means to classify new information, integrating it to the available, social meanings' net, which is applied in the social macro-structure through classification, comparison and categorization processes. Anchorage is the process that allows for "the comprehension of how the elements contribute to express and constitute social relations" (Moscovici, 1961, free translation).

It must be noted that SRs are imbued of both affect and memory, so that emotional aspects are involved in the production of ideas. In this sense, objects can set the representational system in a receptive state that allows for the assimilation and creation of new elements, which contribute to these objects' expression and transformation. Interestingly, Moscovici (1978) stated that SRs contribute to behavior formation, information filtering and interpretation, as well as communication orientation, allowing for the elaboration of a social identity.

Through the use of SRs analysis, stable and contradictory elements of social discourse can be found. It also implicates that the meaning attributed to a given object is an individual's psychosocial construction, where, besides his or her personal history, the history of a group is constructed, that is, a group such individual is part of (Minayo et al., 2000). Besides this, knowledge assimilation is always an active process, as people understand and internalize information according to their own references. In this sense, individuals re-elaborate scientific knowledge based on their own "convenience", that is, according to their available ways and resources (Moscovici, 1978). In order to comprehend SRs, it is fundamental to identify the representation in relation to the specific group or individual who constructs it.

Finally, it can be concluded that an image can correspond to a representation, while a representation is hardly ever an image. Considering that the objectivation process is related to reproducing an image, people can give form to a country, making it tangible. In this context, concepts related to country image are presented below.

\section{COUNTRY IMAGE}

Besides the plethora of definitions observed over the more than 40 years of studies on country image and $\mathrm{COO}$ effect, it is also noted that the focus of the research has naturally changed, from exploratory and descriptive work to application of theoretical concepts. The first empirical test on the influence of the COO on the acceptance and success of a product was carried out by 
Schooler (1965), who found significant differences in the assessment of products that were identical as far as all their attributes were concerned, with the exception of the country specified on the "made in" label.

In 1965, it was important to observe or to confirm the existence of the COO effect and also to indicate which country could be regarded as favorable. Despite studies on the theme indicating that products' $\mathrm{COO}$ may influence the consumer's assessment of these products, Pharr (2005) points out those recent discussions have been emphasizing the importance of product origin in the age of global brands.

For Usunier (2002), production is increasingly globalized, with diversified sources of production, combined in the same end product. Therefore, Usunier (2002) believes that information about products' $\mathrm{COO}$ is often unknown by consumers, or plays a minor role upon the assessment of purchase alternatives. Consequently, Usunier (2002) summarizes the conditions in which the COO effect is present: (1) The consumer needs to consider the information about the product's $\mathrm{COO}$ as relevant for his/her choice process; (2) the consumer needs to be sufficiently motivated to research and compare different origins of products, which occurs when the perceived risk relative to the purchase is high; (3) this motivation depends, in part, on the preference for national products, which is linked to the consumer's patriotism or ethnocentrism, their preference for foreign products or even their preference for specific origins that are associated with certain attributes; (4) the consumer needs to consider this information to be more important than other variables such as price, store's reputation, perceived risk, etc; (5) finally, the consumer needs to easily find this information on the product, or be able to get it from a salesperson.

More recently, studies have tried to relate the COO effect with aspects of consumers' information processing, such as the form by which they acquire, process, and use the information about the country of origin (Gurhan-Canli and Maheswaran, 2000). For example, Aboulnasr (2006) examined the conditions by which the stereotyped information leads to more favorable evaluations of products and countries.

Since the $\mathrm{COO}$ effect refers to the influence that the information on the country of origin exerts on consumer's attitudes and beliefs towards products from that country, it is considered that the effects derived from $\mathrm{COO}$ information are directly affected by the country's image. To Roth and Diamantopoulos (2009), the focus of COO research has gradually shifted from evaluating differences in product evaluations and preferences based on the mere notion of the national origin of a product (the $\mathrm{COO}$ effect) to a more complex construct, namely the image of the countries under consideration. However, as it was pointed out in this paper's introduction, the literature has reached no consensus on how to concepttualize and operationalize the construct "country image", and, as a result, many authors mix the concepts of a specific country's image and the image of the products manufactured in such country. An example of such mistake is Han's (1988) definition, which considers country image as the difference of domestic and foreign products' perceived quality. In the same way, Nagashima (1970), the first author to explicitly define country image, described it as the representation, reputation and stereotype that business men and consumers attribute to a specific country's product. This image is created from variables such as representative products, national characteristics, economic and politic scenery, history and traditions. In their research, Roth and Diamantopoulos (2009) present other authors that have defined the country image as, essentially, a product-related construct.

On the other hand, there are authors that have defined country image focusing on the their role as origins of products and as a generic construct consisting of generalized images created not only by representative products but also by other dimensions (Roth and Diamantopoulos, 2009). For instance, according to Papadopoulos (1993), country image is defined as an image and the thoughts it creates in the consumer's minds. In the same way, Verlegh and Steenkamp (1999) indicate that a country's image refers to mental representations regarding people, products, culture and national symbols of a country. According to theses authors, country images have widely shared cultural stereotypes, which persist even when consumers really try products from this country. These images also contain general impressions regarding these countries and idiosyncratic beliefs about their products. Such beliefs, in their instance, are formed from both direct and indirect experience with these products.

The inconsistency in the definitional domains of the COO construct noted in Roth and Diamantopoulos (2009)'s research and shown above can result in considerable confusion regarding its conceptual specification. Nonetheless, most recent studies of country image definitions include general evaluations a consumer has regarding the quality of a given country's products. The perception a consumer has referring a given country is the way he or she selects, organizes and interprets the stimuli related to this country in a coherent representation (Assael, 1995; Schiffman and Kanuk, 2000).

In an analogy with the definition of brand image proposed by Engel et al. (1995), it can be said that a country's image is a set of existent associations between the country and other information stored in the consumer's memory. The images formed by consumers in relation to a country are based on inferences made from marketing and environment stimuli. In the same line of reasoning, Jaffe and Nebenzahl (2001) define country image as the mental representations people have about countries. The inferences consumers make of a country are related to the beliefs they have about this country, 
which are formed by past associations. These inferences are also based on the signs and symbols associated to this country. The formed country image is, thus, the total perception of a country that consumers have when processing the information from several sources over time.

Gestalt Psychology suggests that image formation is a natural process in the development of an object's total perception (Assael, 1995). As a country image can act as a stereotype (Nagashima, 1970) it can either reflect reality's mental representations or not correspond to them being so, the result of elusive associations or incorrect inferential processes. (Balabanis et al., 1999)

Jaffe and Nebenzahl (2001) explain that a country's image is influenced by the perception people have regarding its people, economic development level and product quality. In this context, Jaffe and Nebenzahl (1984) indicate that choosing a proper quantitative scale for measuring country image has been inquired and reported in both marketing and consumer behavior literature.

According to Roth and Romeo (1992), although country image studies use different variables to assess such image, four elements are commonly present in these studies: Innovation, design, prestige and workmanship. An example of the way country image is measured cited by Roth and Romeo (1992) is the study by Han (1990), who used five items: Technical advancement, prestige value, workmanship, price and serviceability. It can thus be observed that the studies from both Roth and Romeo (1992) and Han (1990) suggest that country image is a one-dimensional concept, which refers just to aspects regarding product-related aspects and not other elements.

However, according to Jaffe and Nebenzahl (2001), the concept of country image cannot be considered as onedimensional. That same assumption has been made in the studies carried out after 1992, which consider COO image as a multidimensional concept and transfer focus from product to country characteristics (Ayrosa, 1998). Besides this, Jaffe and Nebenzahl (2001) believe that other mistakes in country image research are considering this image as an independent element from products' images and considering country image as a static phenomenon. For these authors, a country's image affects their products' one, and, similarly, experience with these products can change their country's image.

Considering country image's multidimensional aspect, Martin and Eroglu (1993) worked with three dimensions, that are, political, economic and technological. On their turn, Pisharodi and Parameswaran (1992) developed their measure of country image in three groups of items, each one with its own dimensions. The first group of items (denominated general country attributes - GCA), aims to capture general attitudes respondents have towards a country, in a general way. The second group of items, general product attributes (GPA), aims to capture general attitudes in relation to general characteristics of the products manufactured in the country being studied, including aspects of these products' promotion and distribution. The third group of items used, denominated specific product attributes (SPA), aims to capture the attitudes towards specific products of the country being studied.

Finally, Nebenzahl et al. (2003) developed a scale for assessing country image, based on the consumer's structure of mental references, rather than the researcher's one, in an approach called "personification". In this study, the authors asked consumers the following question: "A person who buys home appliances manufactured in [name of country] is...", in which [name of country] represents the country whose image is being assessed. When respondents were asked to describe a person who buys a product from a particular country, instead of describing the product itself, the reply obtained is associated with the buyer's own attitudinal, behavioral, social and personality concepts. Respondents' evaluations regarding people who buy products manufactured in a particular country will reflect the image of products manufactured in that country. Thus, the methodology facilitates identifing the perceptual dimensions that consumers use to evaluate products (Nebenzahl et al., 2003). Next, the few Brazilian studies identified about country image and $\mathrm{COO}$ effects are presented.

\section{Brazil's image studies}

In Brazil, studies about the COO effect are still in their beginning, making the present paper a relevant contribution in this area. All the available Brazilian studies have a strong descriptive component, generally intending to detect the existence of a COO effect (Ayrosa, 2000). However, as most of these studies refer to non-Brazilian products, the present paper intended to assess the $\mathrm{COO}$ effect of Brazilian products marketed abroad.

Some of the studies about COO effects on consumers' attitudes towards specific products were the ones carried out by Ayrosa (1991), Carvalho (1993), Chong (1993) and Vazquez (1994). As mentioned earlier, these studies intended to detect the existence of such an effect. These studies were designed as quantitative surveys, which confirmed the predictions related to $\mathrm{COO}$ effects on films, wine and olive oil. Besides this, Carvalho (1993) confirmed that organizational buyers tend to use countryrelated stereotypes when taking buying decision. However, as mentioned earlier, the studies carried out in Brazil did not inquire the $\mathrm{COO}$ effect related to Brazilian products, and neither did use a sample of foreign consumers.

On the other hand, a study in this direction, that is, about the $\mathrm{COO}$ effect of a Brazilian product, was conducted by Vives (2000). The author elaborated a qualitative study about the role local images (that is, 
referring to countries, states, regions or cities) play in value aggregation of specific products, as well as in obtaining competitive advantages based on these products' origin. Besides, Giraldi (2005) also investigated the image of Brazilian products abroad, using quantitative surveys in the Netherlands. International studies regarding $\mathrm{COO}$ effect and involving Brazilian products have observed that Brazil was not one the countries associated with high quality products. An example is the study by Gaedake (1973), who showed that food products, electronic and textile goods manufactured in developing countries were perceived as inferior than American products. In this study, a sample of American students was used, with the following products having being evaluated: Meat products, mushrooms, fruit and vegetables (all of them in can packages). The developing countries inquired were Brazil, Mexico, Argentina and Taiwan.

Stewart and Chan (1993), using tourism buses as the category studied, observed that Mercedes-Benz buses manufactured in Brazil and South Korea had a significant, more unfavorable image when compared to the buses manufactured in Germany. Similarly, Nebenzhal and Jaffe (1997) indicate that many consumers from Israel refused to buy Volkswagen cars made in Brazil, even knowing that the same models were being sold in Germany for higher prices.

It must be stressed out that most of the studies presented above have used quantitative measures of country image, excepting Vives (2000), although this author did not inquire Brazil's image abroad. In fact, Vives (2000) studied French origin denominations in wineries situated in Bourgogne and Champagne, which are acknowledged worldwide for the linking between their products and origin. The author's intention was to identify key-factors related to the success of this origin denomination initiative. Based on the French experience, a case study was organized regarding plantations of special coffee varieties in the Brazilian state of Sao Paulo. Vives (2000) assessed whether or not Brazilian coffee plantations had the same key-factors observed in France. In its turn, the present study aimed to inquire Brazil's image in a qualitative approach, considering the objectivation process described by the SR theory, presented earlier. It is assumed that the theory of SR provides a more holistic stance in order to understand image formation processes that take place within social groups, when compared to quantitative analysis normally employed in studies on country image. This is because people's relationship with the world is invariably mediated by a layer of socially constructed and continuously evolving symbols, or representations, which serve to render the world meaningful for social actors. The theory provides a rich vocabulary to examine the formation, change, and content of these representations, and their relationship to people's actions. Below, the procedures of the empiric study carried out are shown.

\section{Empiric study}

The present study is an exploratory one, as it was planned to help enhance familiarity (Churchill, 1991) with the use of social representation theory to understand and analyze a country's image. To the authors' concern, no paper on this area has addressed this method to analyze country images.

The research design was a qualitative inquiry, which deals with values, beliefs, habits, representations and opinions. Also, it deeply focuses on the complexity of specific, individual or group-related processes, which cannot be reduced to variable operationalization (Minayo et al., 2000). This approach deals with qualitative data analyses, which is pertinent for such social processes, as information does not flow the same way across social groups, leading to ambiguities and imprecision. For comprehending image formation based on the SRs theory's objectivation process, a study about Brazil's image was carried out with Dutch undergraduate students, from the Harleem School of Economics (Netherlands). Such a target population was designed for convenience reasons, regarding easy access to respondents and the support of professors from this college, who made the questions used in the study. Netherlands was the chosen country for it being an important access way for Brazilian products in Europe, with Rotterdam's harbor as the main outpost for Brazilian exportations. Seventy-three students took part of the research, 43 male and 30 female ones. Of all the respondents, only 7 did not know anything about Brazil. Even if respondents are not familiar with Brazil, their Social Representations can act as systems of values, ideas and practices that can establish an order that will enable them to orient themselves in their material and social world (Moscovici, 1978). According to Wagner and Kronberger (2001), social representations aim to transform what is disturbing and unknown into something familiar and known.

The following question was proposed: "Present some words that come to your mind when you think about Brazil". Considering that the objectivation process is related to reproducing a concept as an image, the proposed question was designed to give form to the concept "Brazil", orienting thus the perception and judgments in a socially constructed reality. All participants' answers were assessed using content analysis procedures in consecutive steps, as proposed by Figueiredo (1998) and shown in Table 1.

\section{RESULTS AND DISCUSSIONS}

Considering the question studied, the proposal "some words that come to your mind when you think about Brazil" led to responses related to components transcript to some thematic categories, as seen on Figure 1. Data analysis was carried out using content analysis, according to Bardin (1975). All responses were grouped by similarity, their percentage and frequency and, specially, for responses that were qualitatively different or similar from the other ones.

The categories found can be seen as the result of the schematization process, since respondents' imaging structure is reproduced in a visible form that constitute the represented object (Brazil's image) (Moscovici, 1978). For the first category (denominated "Population"), responses regarded Brazilian population's images, which were divided in three subcategories:

1.) Women: Representations about Brazilian women's beauty and sensuality: "amazingly attractive women" 
Table 1. Content analysis procedures.

\begin{tabular}{ll}
\hline \multicolumn{1}{c}{ MATERIAL TRANSCRIPTION } \\
\hline & A. INITIAL READING \\
& B. MARKING \\
FIRST STEP (PARTICIPANTS) & C. CUTTING \\
& D. FIRST JUNCTION ${ }^{*}$ \\
& E. NOTATION \\
& F. ORGANIZATION AND FIRST SYNTHESIS \\
\hline SECOND JUNCTION ${ }^{* *}$ \\
\hline \multirow{3}{*}{ SECOND STEP } & G. INITIAL READING \\
(CONTENTS) & H. ORGANIZATION \\
& I. NOTATION \\
& J. FINAL WRITING \\
\hline
\end{tabular}

${ }^{*}$ Contents related to several Categories, in the same respondent or group. ${ }^{* *}$ Contents of several respondents or groups, in the same category.
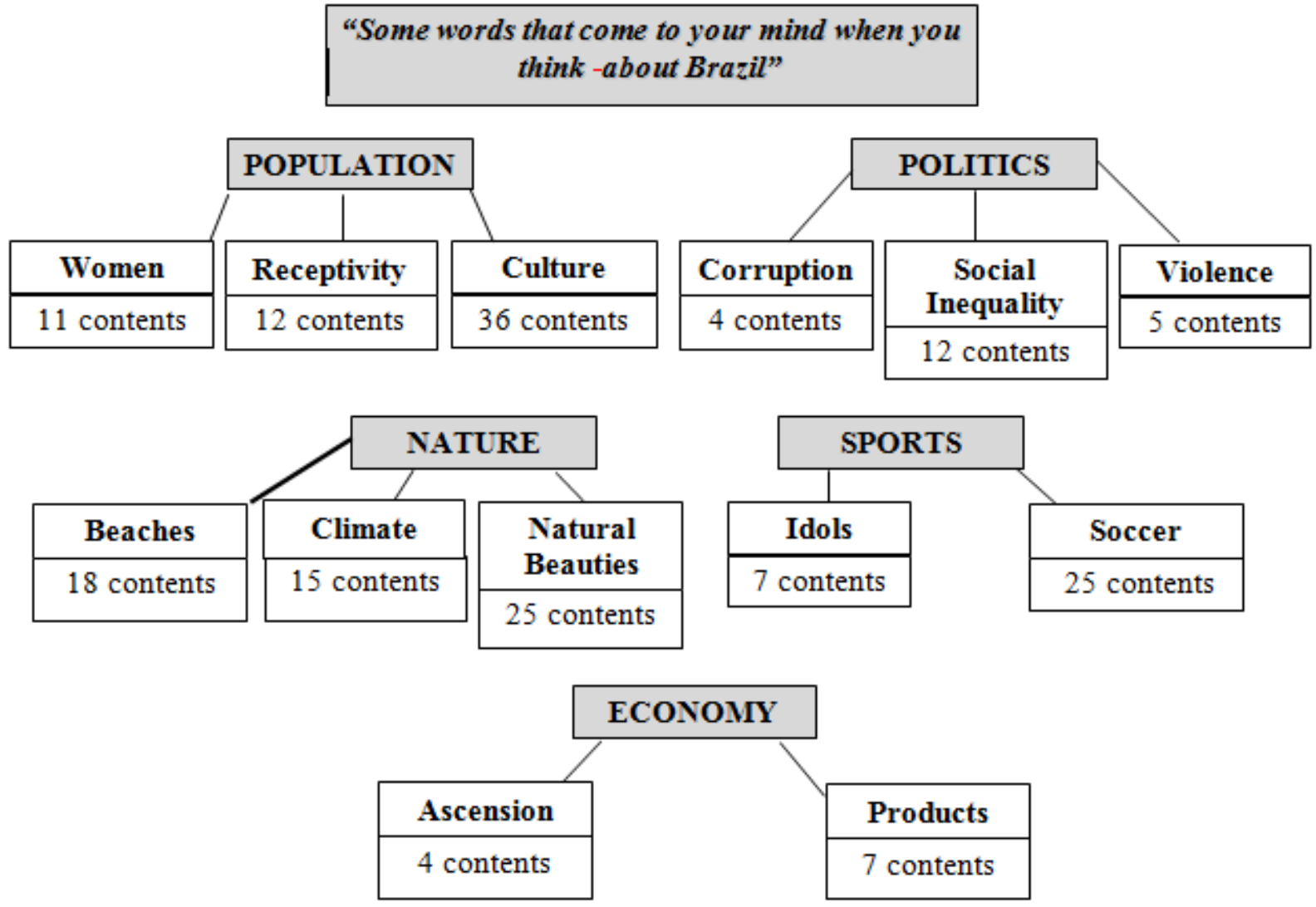

Figure 1. Contents identified in the empirical study.

(Respondent 57 - R.57).

2.) Receptivity: Responses related to Brazilian population's affectivity and hospitable relations: "very friendly people" (R.13).

3.) Culture: Representations about the wide, Brazilian cultural production, varying from typical food to Carnival:
"Brazilian Carnival" (R.71).

It can be seen that the choice of a representation is not arbitrary, since it is related to the stock of knowledge, vocabulary and imagery that this specific group of respondents have in common. To Moscovici (1978), the expressions used reflect their shared identity, history, and 
their everyday "social terrain".

In the second category ("Politics"), the contents regarded negative aspects, subdivided in three categories:

4.) Corruption: Contents related to the images of corrupt political leaders: "(...) poverty, corruption..." (R.67).

5.) Social Inequality: Responses related to social and economic differences, due to public management: "The rich getting richer and the poor getting poorer" (R.58).

6.) Violence: Refers to responses about violent situations and committed crimes: "Lots of crimes!" (R.74).

In the third category ("Nature"), the representations concentrate contents related to Brazil's physical characteristics and climate, which were divided in three subcategories:

7.) Beaches: Contents related to the description and exaltation of Brazilian beaches: "I think about the crystalline waters and white sand" (R.56).

8.) Climate: responses that stress meteorological aspects: "A sunny and hot weather" (R.43).

9.) Natural Beauties: Responses in this subcategory were related to the diversity of Brazilian vegetation, territorial extension and mainly the Amazonian Forest: "The big forest and Amazon River" (R.73)

In the fourth category ("Sports") the respondents emphasized sport idols, big international achievements and mainly soccer. Two subcategories derived from the responses:

10.) Idols: responses about great Brazilian champions: "Ayrton Senna, Formula 1 race" (R.48).

11.) Soccer: In this subcategory, there were many responses regarding only soccer, being the game itself or its idols: "World soccer champion five times" (R.15).

In the category above, it can be clearly seen the objectivation process taking action, since metaphors and icons (such as sports' idols) can be considered examples of objectification (Wagner and Kronberger, 2001).

In the fifth, last category (denominated "Economy"), the representations found were related to Brazilian economy, as well as its exportation products and main economic centers. Again, only two subcategories derived from the responses:

12.) Ascension: representations about Brazil's economic and commercial ascension: "Growing country, technologically and economically as well" (R.13).

13.) Products: In this category, the responses regarded Brazilian products' quality and variety: "Besides this, I associate Brazil to agricultural products" (S.26).

All categories identified (Population, Politics, Nature, Sports and Economy) represent respondents' both perception and judgments, in a socially constructed reality, as the result of the objectivation process. These representations can be expressed in individual cognition and action (as measure in this paper), but they also exist across minds, in the inter-subjective space that is continuously enacted through multiple group members' talk and action. In this case, the represented object (Brazil's image) can be seen as a reference point that the groups have in common, which serves as a common denominator based on which groups engage in some sort of social relations.

\section{FINAL CONSIDERATIONS AND CONCLUSIONS}

The present paper aimed to analyze Brazil's image in light of the SRs theory, considering the objectivation process, in a sample of Dutch young respondents and assessing the answers using content analysis procedures. SRs theory provides a holistic stance from which to understand processes of meaning-making that take place within social groups. Five $\mathrm{CO}$ categories were identified, with their respective subcategories/dimensions. The CO categories were: Population, Politics, Nature, Sports and Economy. The results show that country image is a multidimensional concept, with elements not related to the products made in such countries. Jaffe and Nebenzahl (2001) reached the same conclusion, considering that country image is mediated by product images and other elements.

Furthermore, the present study found five countryimage dimensions, which is more than the three dimensions found by Martin and Eroglu (1993), that are, political, economical and technological. Moreover, Pisharodi and Parameswaran (1992) identified three group items with their own dimensions, as seen in the literature review. Although more dimensions were found in the present study, they are related to both country and products' images, which is also consistent to other reports (Ayrosa, 1998, 2002; Giraldi, 2005).

The results herein reported can be considered an advance in the studies about Brazil's image abroad, through the use of a qualitative method based on SRs theory. The dimensions identified in Brazil's image can have an important implication for companies, who can adopt more effective marketing strategies for their products abroad. This knowledge can help Brazilian companies take more efficient decisions, when they must deal with questions related to $\mathrm{CO}$ in their international marketing activities. Besides this, the results herein reported can offer more elements for the discussion about using Brazil brand in Brazilian products' exporttation, as it was possible to identify the elements related to a process of formal knowledge's construction, that is, how the respondents constructed an image of Brazil. $\mathrm{COO}$ image can, in this sense, become an important tool, as it contains both emotional and intangible components that can affect investment decisions.

A limitation of this study is the very nature of the methodology used. Since it is a qualitative research, the results found cannot be generalized across other segments of respondents or even to other countries' images. To overcome this matter, future studies should 
proceed with qualitative approaches in order to identify the dimensions utilized by foreign consumers to evaluate countries and their products. This applies specially for Brazil, for its growing importance in the international scenario and the small number of studies regarding this country's image abroad. Moreover, since different groups may develop different representations of the same phenomenon depending on their socio-historical contexts, future studies should involve different segments of foreign buyers.

An additional suggestion for future research involves the triangulation between quantitative and qualitative methods of collection and analysis, when focused on the same issue (measuring a country's image). This methodo-logical strategy could show stability (reliability) of the findings presented here. If similar results are obtained when using different research methods, it is reasonable to assume that the method of research did not influence the findings.

\section{REFERENCES}

Aboulnasr K (2006). Country of origin effects: the role of information diagnosticity, information typicality and involvement. Market. Manage. J., 16(1): 1-18.

Anzieu D (1981). The concept of projection in psychology. In: The projective tests, 3rd. ed. Rio de Janeiro, RJ: Campus.

Askegaard S, Ger G (1998). Product-country images: towards a contextualized approach. In: Englis B., Olofsson A., ed. European advances in consumer research, pp. 50-58.

Assael H (1995). Consumer behavior and marketing action. Cincinnati: South-Western College Publishing.

Ayrosa EAT (1991). Perceptions of Brazilian and foreign films: an investigation among university students. Dissertation (Master degree in Business Management): COPPEAD/UFRJ, Rio de Janeiro, 145 pp.

Ayrosa EAT (1998). Image of country: a scale to assess attitudes on individual countries. Annals of ANPAD XXII Annual Meeting, Foz do Iguacu, Brazil, CD-ROM.

Ayrosa EAT (2000). Some notes on the development of research on country-of-origin effects. Interdiscip arche. 26: 181-214.

Ayrosa EAT (2002). Validation of a scale to measure country image in Brazil. In: Annals of BALAS - The Business Association of Latin American Studies Annual Conference: São Paulo, CD-ROM.

Balabanis G, Mueller R, Melewar TC (1999). Country of origin images around the world: can value priorities predict them? In: Proceedings of the $28^{\text {th }}$ EMAC CONFERENCE, 1999, Berlim, CD-ROM.

Bardin L (1975). Content analysis. New York: Editions.

Carvalho VAP (1993). The perception of organizational buyers and the image of country of origin of goods. Dissertation (Master degree in Business Management): COPPEAD / UFRJ, Rio de Janeiro, 101 pp.

Chong AMRV (1993). Influence of country of origin in the evaluation of imported wines. Dissertation (Master degree in Business Management): COPPEAD / UFRJ, Rio de Janeiro, 191...pp.

Churchill GA (1991). Marketing research: methodological foundations. Fort Worth: The Dryden Press.

Engel JF, Blackwell RD, Miniard PW (1995). Consumer behavior. $8^{\text {th }}$. ed. Orlando: The Dryden Press.

Figueiredo MAC (1998). Affective and cognitive scales of attitude: construction, validation and interpretation of results. In: Romanelli, G.; BIASOLI-ALVES, Z.M.M. (Ed.) Dialogues Methodological Research on Practice. Ribeirão Preto: Legis Summa, 1998. p. 51-70.

Freud S (2000). The interpretation of dreams. Commemorative Edition of 100 years (WI de Oliveira, translator). Rio de Janeiro: Imago. (originally published in 1900).

Gaedake R (1973). Consumer attitudes toward products "made in" developing countries. J. Retailing 2(49): 13-26.
Giraldi JME (2005). The influence of Brazil's image in the attitude of foreign consumers in relation to Brazilian products: a study with Dutch university students. dissertation (Master degree in Business Management): FEA/USP, São Paulo, 158 pp.

Gurhan-Canli Z, Maheswaran D (2000). Cultural variations in country of origin effects. J. Mark. Res. 37(3): 309-317.

Han CM (1988). The role of consumer patriotism in the choice of domestic versus foreign products. J. Advert. Res., 29(3): 25-32.

Han CM (1989). Country image: halo or summary construct? J. Market. Res., 26(5): 222-229.

Han CM (1990). Testing the role of country image in consumer choice behaviour. Eur. J. Market., 24(6): 24-40.

ittersum KV, Candel MJJM, Meulenberg MTG (2003) The influence of the image of a product's region of origin on product evaluation". J. Bus. Res., 56(3): 215-26.

Jaffe ED, Nebenzahl ID (1984). Alternative questionnaire formats for country image studies. J. Mark. Res., 21(4): 463-71.

Jaffe ED, Nebenzahl ID (2001). National image and competitive advantage: the theory and practice of country-of-origin effect. Copenhagen: Copenhagen Business School Press.

Jodelet D (1984). Representing social phenomena, concepts and theories. In: Moscovici, S. (Org.). Social psychology. 2nd. ed. Barcelona / Buenos Aires / Mexico: Polity Press, pp. 469-494.

Jodelet D (1989a). Social representations. Paris: PUF.

Jodelet D (1989b). Folie et représentations sociales. Paris: PUF.

Jovchelovitch S (1994). Texts in Social Representation. Petropolis, RJ: Vozes.

Laplanche J (2001). Projection. In: Psychoanalytic Vocabulary / Laplanche and Pontalis, 4th. ed. São Paulo: Martins Fontes, pp. 373380.

Laroche M, Papadopoulos N, Heslop LA, Mourali M (2005). The influence of country image structure on consumer evaluations of foreign products. Int. Mark. Rev., 22(1): 96-115.

Leão ALMS, Souza Neto AF, Mello SCB (2007). Understanding the values of the brands: the list of values applied in different industries. RAC 11(2): 27-48.

Lyman B (1984). An experiential theory of emotion: a partial outline with implications for research. JMI 8: 77-86.

Mandler G (1982). The Structure for Value: Accounting for Taste. In: Clarke, M. S., Fiske, S. T. (eds): Affect and Cognition: The 17th Carnegie Symposium on Cognition. Hillsdale, NJ: Erlbaum, p. 3-36.

Martin IM, Eroglu S (1993). Measuring a multi-dimensional construct: country image. J. Bus. Res., 28(3): 191-210.

McLeod SA (2007a). Perception Theory. In: Simply Psychology [Online]. (2007a). Available in [http://www.simplypsychology.pwp.blueyonder.co.uk/perceptiontheories.html]. Access: March 21st, 2009.

McLeod SA (2007b). Perceptual Set. In Simply Psychology [On-line]. Available

[http://www.simplypsychology.pwp.blueyonder.co.uk/perceptual set. html]. Access: March 21st, 2009.

Minayo MCS (1994). The challenge of knowledge: qualitative health research. Sao Paulo / Rio de Janeiro: Hucitec-Abrasco.

Minayo MCS, Hartz ZMA, Buss PM (2000). Quality of life and health: a necessary debate. Bull. World Health Organ. 5(1): 7-17.

Moscovici S (1961). Psychoanalysis its image and public. Paris: Presses Universitaires de France.

Moscovici S (1978). A social representação da Psicanálise. Rio de Janeiro: Zahar.

Nagashima A (1970). A comparison of Japanese and U.S. attitudes towards foreign products. J. Mark., 34: 68-74.

Nebenzahl ID, Jaffe ED (1997). Measuring the joint effect of brand and country image in consumer evaluation of global products. J. Mark. Prod., 3(3): 190-205.

Nebenzahl ID, Jaffe ED, Usunier JC (2003). Personifying country of origin research. Manag. Int. Rev., 43(4): 383-406.

Papadopoulos N (1993). What product and country images are and are not. In: Papadopoulos N, Heslop LA. Product-country images: impact and role in international marketing. London: Haworth Press, pp. 3-38.

Pasian SR (2000). O Psicodiagnóstico de Rorschach no mundo atual. In: The Rorschach psychodiagnostic in adults: Atlas, rules and reflections. New York: Psychologist, pp. 22-25. 
Pharr JM (2005). Synthesizing country-of-origin research from the last decade: is the concept still salient in an era of global brands? JMTP 13(4): $34-45$.

Pisharodi RM, Parameswaran R (1992). Confirmatory factor analysis of a country-of-origin scale: initial results. Adv. Consum. Res. 19(1): 706-714.

Poiesz TBC (1989). The image concept: its place in consumer psychology. J. Econ. Psychol., 10: 457-472.

Robbins SP (1999). Perception and individual decision making. In: Behavior organizacional, 8th. Ed., Rio de Janeiro: LTC, pp. 60-84.

Roth MS, Romeo JB (1992). Matching product category and country image perceptions: a framework for managing country-of-origin effects. J. Int. Bus. Stud., 23(3): 477-497.

Roth KP, Diamantopoulos A (2009). Advancing the country image construct. J. Bus. Res., 62: 726-740.

Schiffman LG, Kanuk LL (2000). Consumer behavior. Upper Saddle River: Prentice Hall.

Schooler RD (1965). Product bias in the Central American common market. J. Market. Res., Chicago, N. 2, pp. 394-397.

Schultz DP, Schultz SE (1992). Influences on the Physiological Psychology. In: History of modern psychology, 5th. Ed New York: Cultrix, pp. 56-74.

Serpa DA, Avila MG (2004). Perception about price and value: a test experimental. RAC 3(2), available in: [http://www.scielo.br/scielo.php?script=sci_arttext\&pid=S167656482004000200012\&lng=es\&nrm=iso]. Access: March 21st,, 2009.

Stewart S, Chan C (1993). Influence of place-of-production on industrial buyers' perceptions. In: Papadopoulos C, Heslop L (Eds.). Product and country images. New York: International Business Press, pp. 223-244.

Taylor SE, Crocker J (1981). Schematic Bases of Social Information Processing. In: Higgins ET, Herman CP, Zanna MP (eds): Social Cognition: The Ontario Symposium. Hillsdale, NJ: Erlbaum, v.1, pp. 89-134.

Usunier JC (2002). The country of origin of the influence he still consumer ratings? Rev. Fr. Mark., 189/190: 49-67.

Usunier JC (2006). Relevance in business research: the case of country-of-origin research in marketing. Eur. Manage. Rev., 3: 60-73.

Vazquez MMF (1994). Influence of country of origin on perceptions of organizational buyers for some food products. . Dissertation (Master degree in Business Management): COPPEAD / UFRJ, Rio de Janeiro, $181 \mathrm{pp}$.
Verlegh PWJ, Althuijzen NAP, Vroegh, TP (1999). Country stereotypes: cognition, affect and product judgment. In: Proceedings of the $28^{\text {th }}$ EMAC Conference, Berlim, CD-ROM.

Verlegh PMJ, Steenkamp JBEM (1999). A review and meta-analysis of country-of-origin research. J. Econ. Psychol., 20(5): 521-546.

Vives W (2000). The image of the place of origin of products and competitive advantages: a case study of specialty coffee in Sao Paulo. Dissertation (Master degree in Business Management): Fundacao Getulio Vargas, Sao Paulo, 120 pp.

Wagner W, Kronberger N (2001). Killer tomatoes! Collective symbolic coping with biotechnology. In: Deaux K, Philogene $\mathrm{G}(\mathrm{Eds}$.). Representations of the social: bridging theoretical traditions. Oxford: Blackwell, p. 147-164.

Zhang Y (1997). Country-of-origin effect: the moderating function of individual difference in information processing. Int. Mark. Rev., 14(4): 266-287. 